\title{
Research on "Combination of Medical Treatment and Endowment" from the Perspective of Digital Economy
}

\author{
SUI Dang-chen, GUAN Yi-han* \\ School of International Business, Shanxi Normal University \\ Xi'an 710119, China
}

\begin{abstract}
With the rapid rise of aging population in China, the problem of ageing is becoming increasingly prominent. With the rapid development of digital economy, the effective combination of digital technologies such as Internet and a large number of innovative subjects has produced new benefits and values. How to make use of the "combination of medical treatment and endowment" pension model under the background of digital economy has become an increasingly prominent issue. This article, based on the perspective of digital economy, analyzes the status quo, responds to opportunities and challenges of the "combination of medical treatment and endowment", finally puts forward countermeasures and suggestions to perfect the mode of "combining medical care with nursing care" in China, so as to meet the multi-level needs of the elderly under the background of digital economy, and promote healthy aging and improve the well-being of the elderly.
\end{abstract}

Keywords-Digital economy; Combination of medical treatment and endowment; Pension services

\section{INTRODUCTION}

The G20 digital economy development and cooperation initiative was proposed at the G20 summit in hangzhou, China in 2016, which clarified the connotation of the digital economy. China's information and communications research institute believes that the knowledge of the digital economy is based on digital and information as the key factors of production, with digital technology innovation as the core driving force, with modern information network as the important carrier, through the depth of integration of digital technology and the real economy, constantly improve the level of the traditional industry of digital, intelligent, increasing the reconstruction of economic development and government governance mode of the new economic form.

In recent years, with the social realities such as aging, emptying, incapacitation, reduction and living alone brought by deep aging and the increasingly prominent health problems of the elderly, the needs of the elderly for medical care and health services have significantly increased. The traditional pension function is gradually weakened, which makes the "combination of medical treatment and endowment" pension model come into being. The application of "Internet +" provides a higher platform for this new pension model. Li mo

About the author: Sui Dangchen (1963-), male, Linyi, Shaanxi, Professor of International Business School, Shaanxi Normal University, doctoral tutor, mainly engaged in public finance, social security and organizational behavior research;

Guan Yihan (1993-), Female, Xvchang, Henan, Master graduate student of International Business School, Shaanxi Normal University, mainly engaged in the theoretical study of national economy.
(2016) believes that the "Internet + " model of medical treatment combined with endowment will be integrated into the intelligent functions of the network information platform, and traditional medical care and maintenance will be based on the integrated model of Internet to provide medical and psychological care for the elderly. Sui Dangchen (2017) argue that the rapid development of Internet technology has also made "Internet + " model of medical treatment combined with endowment will be faced with a rare opportunity and challenge. Through the analysis of China's current situation, it should be drawn from three aspects: government level, offline service capability and information technology support. The perfection enables the elderly to enjoy the convenience brought by "Internet + " model of medical treatment combined with endowment.

Ma longfei (2017) believes that the mode of "combination of medical treatment and endowment" has been vigorously promoted by the country, but the serious shortage of medical resources and its imbalance restrict the development of "combination of medical treatment and endowment". Meanwhile, the rapid development of Internet technology provides technical support to solve the problems mentioned above.

There are relatively few opportunities and challenges in the research on "medical and endowment combined" endowment services in the background of digital economy in China. Based on this, this paper will analyze the opportunities and challenges faced by the "combination of medical treatment and endowment" in the context of digital economy and put forward policy recommendations.

\section{OPPORTUNITIES BROUGHT BY THE DIGITAL ECONOMY TO THE COMBINATION OF MEDICAL CARE AND OLD-AGE CARE SERVICES}

\section{A. Rapid development of the digital economy}

The "Internet + " strategy first put forward by premier li keqiang in the government work report at the beginning of 2015 has been rooted in China ever since. On March 1, 2015, the British government released the digital Britain strategy and said that it would create a digital economy that would benefit everyone to ensure that digital dividends would cover the 
whole country. China continued to define the innovationdriven policy in the 2017 government work report, promoting the in-depth development of "Internet+" and promoting the rapid growth of the digital economy. According to the " Internet + " index report (2018) released by tencent research institute on April 12, 2018 at the China "Internet +" digital economy summit, the national digital economy volume in 2017 was 26.70 trillion yuan, up 17.24 percent from 22.77 trillion yuan in the same period last year. The digital economy's share of gross domestic product also rose from 30.61 per cent to 32.28 percent. China's GDP growth rate was 6.9 percent in 2017, and the proportion of digital economy in GDP also increased by 1.67 percentage points. The data also shows that the penetration rate of digital technology in the economic field is constantly improving, which meets the requirements of "high-quality" growth. And according to the calculation of the new framework system, the sum of "Internet +" index in 2017 is 348.69 points, up 86.74 points from the previous year. Among them, the medical index continues to be the leading position in the digital economy. The so-called material basis determines the superstructure, the rapid development of digital economy, its huge development scale and its advanced and Shared nature will upgrade the development of the combination of medical treatment and endowment, expand the development space, and improve the competitive advantage.

TABLE I. CHINA'S DIGITAL ECONOMY VOLUME AND DIGITAL INDEX UNIT: RMB 100 MILLION

\begin{tabular}{|c|c|c|c|c|c|}
\hline Year & GDP & GDPgrowth (\%) & $\begin{array}{c}\text { Total digital } \\
\text { economy }\end{array}$ & $\begin{array}{c}\text { Digital } \\
\text { economy/GDP } \\
(\%)\end{array}$ & $\begin{array}{c}\text { Internet digital } \\
\text { economy index }\end{array}$ \\
\hline 2015 & 676.708 & 6.9 & 约 18 & 约 26.60 & 100 \\
\hline 2016 & 744.127 & 6.7 & 22.77 & 30.61 & 261.95 \\
\hline 2017 & 827.122 & 6.9 & 26.70 & 32.28 & 348.69 \\
\hline
\end{tabular}

a. Note: Data from China's "Internet +" digital economy index (2015); Data from China's "Internet +" digital economy index (2016);Data from China's "Internet +" digital economy index (2017);China's national bureau

B. The development of digital economy promotes the effective connection between online and offline and the organic combination of contents

Firstly, under the background of digital economy, the pension mode of "combination of medical treatment and endowment" is integrated into the intelligent function of network information platform. Include elderly care in health care. By using mobile apps, smart wearable devices, interactive video detection system, etc., the elderly are continuously tracked and stored on their health status, and then personal electronic health archives are established to form a complete medical information database, so as to help the elderly to timely discover various chronic diseases. At the same time, doctors use health data of the elderly to improve medical efficiency. Secondly, the rapid development of artificial intelligence under the digital economy also creates favorable conditions for the organic combination of "combination of medical treatment and endowment" pension service industry. So that the medical aspects of health prevention, medical services, rehabilitation and nursing care, mental comfort, five aspects organically combined.

\section{The development of digital economy optimizes the allocation of medical care and endowment resources, and gradually forms the "combination of medical treatment and endowment " based on family}

With the aggravation of aging, China's existing medical resources are insufficient, while some pension service institutions have idle resources. First, the development of digital economy enables hospitals and governments to extensively collect the actual needs of elderly people for elderly care resources and medical resources, so that the government can allocate elderly care resources according to the actual needs of elderly people, and hospitals can reasonably match patients with medical resources through data analysis. Secondly, the digital network platform helps the elderly to communicate with the medical staff through multiple channels. The elderly get the online medical staff's consultation services and guidance through the network at home, and achieve the rehabilitation and nursing independently, so as to alleviate the crowded phenomenon of medical institutions. In addition, the gradual maturity of artificial intelligence technology in the digital economy enables the effective combination of medical and pension contents. Artificial intelligence robots are gradually replacing human work, and the elderly can be taken care of by artificial intelligence robots in their homes.

\section{THE CHALLENGE OF THE DIGITAL ECONOMY TO THE COMBINATION OF MEDICA TREATMENT AND ENDOWMENT}

\section{A. Under the digital economy, the related policies of "combination of medical treatment and endowment " are not perfect}

In the digital economy, there are still many deficiencies and imperfections in the implementation of the "combination of medical care and support" policy and system construction. For example, in the "combination of medical and nursing care", "medical" and "nursing" are originally two sectors, which will involve more sectors and industries from the perspective of digital economy, leading to the "fragmentation" and lack of standards in the construction of pension system under the digital economy. The "fragmentation" of the system is reflected in the fact that China's digital pension industry has not yet formed a unified and coherent system. The policies related to digital endowment come from multiple departments, whose standards are not consistent, which will cause problems 
such as "difficult implementation" of relevant policies. Digital endowment and digital medical care are new things for pension service institutions, which really need the support of relevant government policies and innovation of management methods.

\section{B. The lack of personalized services in the digital economy and the mismatch between supply and demand}

First of all, the medical and nursing service for the elderly provides organic integrated services according to the actual needs of the elderly. However, the actual conditions such as income and health status of the elderly vary greatly, and the health status of the elderly often exists in different stages such as disease, treatment and rehabilitation nursing. In addition, most elderly people's demands for maintenance services and medical services are fragmented, which makes it difficult to propose targeted and systematic service demands, thus hindering the implementation of personalized services. Secondly, the demand for medical information and consultation services through search engines is huge on average every day. However, there are still some obstacles between the supply side and the demand side of medical services due to the limitations of high professionalism and insufficient information openness.

\section{The Internet penetration rate of the elderly in the digital economy is low and the professional requirements are high}

First of all, there are more and more services provided to the elderly by the application of Internet digital technology in the "combination of medical treatment and endowment". However, the Internet penetration rate among the elderly is still quite low. This situation severely limits the development of intelligent and digital endowment in the digital economy. Secondly, the development of the "combination of medical treatment and endowment " pension service industry is the deep integration of the two fields of medical and endowment, not only the integration of professional equipment and other hardware, but also the deep integration of management concepts and professional qualities of service personnel and other software. However, the management personnel of the pension service institutions can truly master the shortage of high-end management talents in the pension service industry of the two fields of management standard. The development of digital technology, the application of most intelligent devices, also put forward certain requirements for professionalism.

\section{Cyber security issues are prominent in the digital economy}

In December 2015, a cyberattack on Ukraine's power company left more than half of the country's homes without power for several hours. In May 2017, the perpetual blue virus invaded more than 100 countries, paralyzing many important systems. The rapid development of big data, cloud computing and the Internet of things has made cyber security an urgent problem to be solved. The core technology of network security is controlled by others, which makes enterprise business stagnate. The consequences of the core technology being subject to human control are surveillance, hijacking, Trojan virus, lock-up, etc. At present, Internet technology and artificial intelligence are applied in various service industries, such as medical care and elderly care, and infiltrate into all walks of life. Cyber security is a threat to our daily life.

\section{Policy Suggestions ON THE COMBINATION OF} MEDICAL CARE AND PENSION SERVICE UNDER THE DIGITAL ECONOMY

\section{A. Improve policies and innovate management methods}

Digitized old-age care is a new mode of old-age care, and a series of digitized industry standards are recommended to guide and regulate it. Such as access standard, construction and equipment configuration standard, service standard, evaluation standard and charge standard. In terms of laws and regulations, it is suggested to strengthen the introduction of local laws and regulations, and make clear provisions on specific matters involving digital services, such as "combination of medical treatment and endowment", medical services and designated medical insurance, so as to form a legal guarantee for the development of digital "combination of medical treatment and endowment". In addition, a service management department of "combination of medical treatment and endowment" was set up to provide professional services for the elderly in the "combination of medical treatment and endowment" service institutions, so as to make the rights and responsibilities clear. The digital process is used to innovate the management mode so as to make the "combination of medical treatment and endowment" for the aged more smoothly from the perspective of digital economy.

\section{B. Establish a comprehensive management system combining medical treatment and endowment}

Relying on the digital technology to document the daily health status of the elderly and the history of their illness in the information system, the nursing team will make a service management plan for the elderly based on the historical information and the actual situation. Provide personalized elderly care services for the elderly. Secondly, a multi-level and mobile service system is established in a variety of different types of "medical and nursing union" services, such as hospitals, nursing institutions, nursing homes, communities and homes, so as to form an interconnected and interconnected service network. Thirdly, the three-level supply mode of "core hospital + basic health service institution + digital family doctor" is adopted. With big hospitals as the core, grassroots health service agencies as the center, and digital family doctors as the main entrance, the "'" last kilometer" "of medical benefit to the people is achieved through the Internet, big data, artificial intelligence and other technologies. By passively accepting patients' consultation and providing allround, full-cycle medical and health services, the contradictions and obstacles between the demand side and the supply side can be effectively eliminated. 


\section{Construction of an intelligent perception service platform for the elderly and transformation of service delivery methods}

In the context of digital economy, the establishment of intelligent perception service platform for the elderly should realize the intelligentization of services from three aspects: information perception, service mining and process reengineering. The intelligent perception service platform is built from three aspects. Firstly, the integrated sensing equipment and facilities can comprehensively perceive various data indicators of the elderly. Comprehensive data information on the home living status, home environment status, safety status, location status and daily health status of the elderly were collected. Second, integrate the service expert system to provide intelligent decision support. Through the analysis and mining of large-scale data of the elderly, the service needs of the elderly can be accurately positioned, the potential service needs of the elderly can be found, the early warning information of the status of the elderly can be provided, and the real-time reminder of the status of the elderly and the decision-making support of the service plan can be provided for the care managers. Finally, the service process is reconstructed to establish self-service system and remote service support. The elderly service process is reconstructed, the service mode based on Internet is designed, and the selfservice system and remote service mode are established. By integrating expert systems across professional fields, the elderly and their guardians are provided with simple and understandable operation and conclusion, and the services that traditionally need to be provided by professionals can be completed by the elderly or their guardians independently.

\section{Enhance the ability of independent innovation and establish a network security system}

In the face of extremely complex network environment, enhance the ability of independent innovation, build a network security protection system, and build a network security concept. First, enhance the ability of independent innovation. The core technology can not be controlled by others, promoting the domestic operating system, replacing Microsoft, Intel, with their own software. Second, establish a network security protection system. Active immunity to possible threats means protection when calculating. The whole process is visible and controllable. Set up programs such as identity decryption, state measurement, encryption and storage protection, and timely identify elements that are or are not their own. Thus the exclusion of harmful substances (attackers), to ensure health. Thirdly, build network security concept. All industries should be deeply aware of the threat of network security and form a network security concept. Companies and governments can work together to overcome technical difficulties, give full play to institutional and market advantages, keep core technology development free of control, and provide solid technical support for network security.

\section{SUMMARY}

Since the proposal of "the combination of medical treatment and endowment" has been in development till now, from germination to gradual development and maturity, the research on the mode of "the combination of medical treatment and endowment" has provided a lot of effective Suggestions and measures to solve the problems in the real world. However, with the rapid development of digital economy today, the combination of digital intelligence and "combination of medical treatment and endowment" can improve the effective utilization of resources. However, its digital intellectualization is still at the initial stage of development, and there are many problems to be further developed. Further research is needed to promote digital smart care.

\section{REFERENCE}

[1] Li Mo. Study on the combination of medical treatment and endowment model from the perspective of "Internet $+"[\mathrm{~J}]$. Chinese hospital management,2016,16, (99): 171-181. (In Chinese)

[2] Xu Zhijie. Application of "Internet + medical treatment" in the service strategy and guarantee path of "combination of medical treatment and endowment" [N]. Special forum.2016 (05) :28-33. (In Chinese)

[3] Yuan Xiaohang. Research on institutional endowment model innovation of "combination of medical treatment and endowment" [D]. Master of zhejiang university,2013. (In Chinese)

[4] Zhang Yue, Zhu Qinghua. Research on the integration of intelligent elderly care technology and medicaltreatment and endowment combined mode - Summary of the 5th BBS conference on intelligent elderly care and intelligent medical development in 2018[J]. Book intelligence knowledge, 2018 (5) : 124-128.

[5] Liu Hao and Zou Ling. Discussion on the new mode of intelligent medical care based on Internet $+[\mathrm{J}]$. Chinese hospital management,2018(5):56-57. (In Chinese)

[6] Sui Dangchen. Study on the development of the pension mode of "combination of Internet and medical care" [J]. Scientific research on aging,2017 (5). (In Chinese)

[7] Xing Yanan. Elements and advantage analysis of "Internet +" medical treatment and endowment combination[J].Medicine and society,2018(31). (In Chinese)

[8] Wu Fei. Research and application based on the big data cloud computing service platform for health and elderly care. China development [J],2017(17). (In Chinese)

[9] Zhang Xiangeng. Research progress of digital intelligent pension model. Chinese journal of gerontology [J],2017(37). (In Chinese)

[10] G20 digital economy development and cooperation initiative [EB/OL]. (2016-09-29) [2017-02-28]. HTTP: / / http://www.cac.gov.cn/201609/29/c 1119648520.htm. (In Chinese)

[11] China academy of information and communication. China Digital Economy Development White Paper(2017)[R/OL].(2017-07-13)[201707-26]. http://www.caict.Ac.Cn/kxyj/QWFB/BPS/201707/P0201707134080292 02449. PDF. (In Chinese) 